\title{
Density-Viscosity Product of Small-Volume Ionic Liquid Samples Using Quartz Crystal Impedance Analysis
}

\author{
Glen McHale, ${ }^{, \dagger}$ Chris Hardacre, ${ }^{\ddagger}$ Rile Ge, ${ }^{\ddagger}$ Nicola Doy, ${ }^{\dagger}$ Ray W. K. Allen, ${ }^{\S}$ Jordan M. Maclnnes, ${ }^{\S}$ \\ Mark R. Bown, $\$$ and Michael I. Newton ${ }^{\dagger}$
}

\begin{abstract}
School of Science \& Technology, Nottingham Trent University, Clifton Lane, Nottingham NG11 8NS, U.K., QUILL Center, School of Chemistry \& Chemical Engineering, Queens University Belfast, Belfast BT9 5AG, Antrim, North Ireland, and Department of Chemical \& Process Engineering, University of Sheffield, Newcastle St, Sheffield S1 3JD, U.K.
\end{abstract}

Quartz crystal impedance analysis has been developed as a technique to assess whether room-temperature ionic liquids are Newtonian fluids and as a small-volume method for determining the values of their viscosity-density product, $\rho \eta$. Changes in the impedance spectrum of a 5-MHz fundamental frequency quartz crystal induced by a water-miscible room-temperature ionic liquid, 1-butyl-3-methylimiclazolium trifluoromethylsulfonate $\left(\left[\mathrm{C}_{4} \mathrm{mim}\right][\mathrm{OTf}]\right)$, were measured. From coupled frequency shift and bandwidth changes as the concentration was varied from 0 to $100 \%$ ionic liquid, it was determined that this liquid provided a Newtonian response. A second water-immiscible ionic liquid, 1-butyl3-methylimidazolium bis(trifluoromethanesulfonyl)imide $\left[\mathrm{C}_{4} \mathrm{mim}\right]\left[\mathrm{NTf}_{2}\right]$, with concentration varied using methanol, was tested and also found to provide a Newtonian response. In both cases, the values of the square root of the viscositydensity product deduced from the small-volume quartz crystal technique were consistent with those measured using a viscometer and density meter. The third harmonic of the crystal was found to provide the closest agreement between the two measurement methods; the pure ionic liquids had the largest difference of $\sim 10 \%$. In addition, 18 pure ionic liquids were tested, and for 11 of these, good-quality frequency shift and bandwidth data were obtained; these 12 all had a Newtonian response. The frequency shift of the third harmonic was found to vary linearly with square root of viscosity-density product of the pure ionic liquids up to a value of $\sqrt{ }(\rho \eta) \approx 18 \mathrm{~kg} \mathrm{~m}^{-2} \mathrm{~s}^{-1 / 2}$, but with a slope $10 \%$ smaller than that predicted by the Kanazawa and Gordon equation. It is envisaged that the quartz crystal technique could be used in a high-throughput microfluidic system for characterizing ionic liquids.

Over the past decade, the drive toward cleaner industrial processes has led to the development of ionic liquids as alternative, environmentally friendly, solvents. ${ }^{1,2}$ Ionic liquids provide good solvation with a range of compounds, have low volatility, are nonflammable, have a wide liquid range with temperature, and have tunable physical properties and a wide electrochemical

* To whom correspondence should be addressed. E-mail: glen.mchale@ ntu.ac.uk.

${ }^{\dagger}$ Nottingham Trent University.

Queens University Belfast.

$\S$ University of Sheffield. window. ${ }^{3,4}$ They comprise solely ions that are liquid at room temperature and can be considered designer solvents with over 1 million simple ionic liquids alone. Their use with a range of reactions, such as Heck and Suzuki cross-coupling, hydrogenations, oxidations, Friedel-Crafts, Diels-Alder, and polymerization is favored because of the control of selectivity that can be achieved and the ease of recyclability of the catalysts. ${ }^{5-7}$ Ionic liquids have the potential for a wide range of applications including catalysis, ${ }^{5-7}$ organic synthesis, ${ }^{8}$ electrochemistry, ${ }^{9,10}$ separations and extractions, ${ }^{11,12}$ liquid crystals, ${ }^{13-15}$ and analytical solvents and coatings. ${ }^{16}$ However, the data on their physical properties as a function of chemical composition are limited, and extending the range of known data is difficult due to the expense and difficulty of producing large volumes of pure liquids for characterization.

Acoustic wave microsensors, such as the quartz crystal microbalance (QCM), are widely used for studying the properties of small-volume samples of liquids, the attachment of mass from the liquid phase and in situ determination of the properties of surface coatings, such as electrodeposited polymers, during the deposition process. ${ }^{17-19}$ A QCM operates by creating a highfrequency, typically $5 \mathrm{MHz}$, shear mode oscillation of the surface. When operated in a liquid environment, this surface oscillation entrains liquid and creates an oscillation, which for a Newtonian liquid decays within a penetration depth of the interface $\delta=(\eta /$

(1) Earle, M. J.; Seddon, K. R. Pure Appl. Chem. 2000, 72, 1391-1398.

(2) Andrade, C. K. Z.; Alves, L. M. Curr. Org. Chem. 2005, 9, 195-218.

(3) Koel, M. Crit. Rev. Anal. Chem. 2005, 35, 177-192.

(4) Wasserscheid, P.; Welton, T. Ionic liquids in synthesis, 2nd ed.; Wiley VCH: Weinheim, 2007

(5) Sheldon, R. Chem. Commun. 2001, (23), 2399-2407.

(6) Gordon, C. M. Appl. Catal. 2001, A222, 101-117.

(7) Dupont, J.; de Souza, R. F.; Suarez, P. A. Z. Chem. Rev. 2002, 102, 36673691.

(8) Cave, G. W. V.; Raston, C. L.; Scott, J. L. Chem. Commun. 2001, (21), 2159-2169.

(9) Chen, P. Y.; Lin, Y. F.; Sun, I. W. J. Electrochem. Soc. 1999, 146, 32903294.

(10) Endres, F. Chem. Phys. Chem. 2002, 3, 144.

(11) Wei, G. T.; Yang, Z. S.; Chen, C. J. Anal. Chim. Acta 2003, 488, 183-192.

(12) Zhao, H.; Xia, S. Q.; Ma, P. S. J. Chem. Technol. Biotechnol. 2005, 80, 10891096.

(13) Bowlas, C. J.; Bruce, D. W.; Seddon, K. R. Chem. Commun. 1996, (14), 1625-1626.

(14) Abdallah, D. J.; Robertson, A.; Hsu, H. F.; Weiss, R. G. J. Am. Chem. Soc. 2000, 122, 3053-3062.

(15) Bradley, A. E.; Hardacre, C.; Holbrey, J. D.; Johnston, S.; McMath, S. E. J.; Nieuwenhuyzen, M. Chem. Mater. 2002, 14, 629-635.

(16) Qin, W. D.; Wei, H. P.; Li, S. F. Y. J. Chromatogr., A 2003, 985, 447-454. 
Table 1. Halide Content, Water Content in Mass Fractions, Viscosity, and Density of lonic Liquids Measured Using a Viscometer and Density Meter in This Study (at $25^{\circ} \mathrm{C}$ )

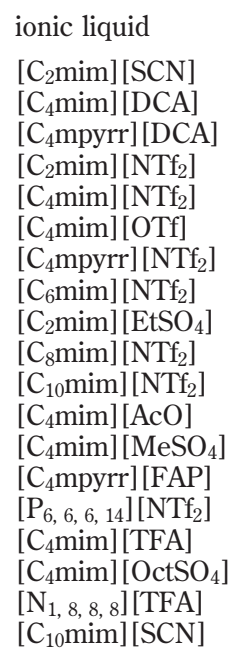

viscosity (cP)
23.6
28.8
36.5
36.5
50.5
83.2
79.3
80.1
98.4
95.0
120.2
139.7
188.0
221.0
335.9
418.5
888.6
1708
683.7

density $\left(\mathrm{g} \mathrm{cm}^{-3}\right)$
1.118
1.059
1.013
1.520
1.436
1.292
1.395
1.357
1.237
1.321
1.279
1.243
1.208
1.580
1.065
1.068
1.072
0.966
1.011

$\left[\mathrm{H}_{2} \mathrm{O}\right](w \mathrm{wt})$
0.0307
0.0256
0.0235
0.0100
0.0096
0.0681
0.0010
0.0013
0.0279
0.0032
0.0052
0.0746
0.0067
0.0132
0.0095
0.0744
0.0113
0.0108
0.0307

[halide] (ppm)

$<5$
1830
1790
$<5$
$<5$
$<5$
$<5$
$<5$
$-a$
$<5$
$<5$
$<10$
$<5$
$<100$
$<5$
$<5$
$<7$
$<5$
$<5$

${ }^{a}$ Halide-free preparation. $\left[\mathrm{C}_{n} \text { mim }\right]^{+}=1$-alkyl-3-methyl imidazolium; $\left[\mathrm{C}_{4}\right.$ mpyrr $]=1$-butyl-1-methylpyrrolidinium; $\left[\mathrm{N}_{1,8,8,8}\right]^{+}=$methyl, triocytlammonium; $\left[\mathrm{P}_{6,6,6,14}\right]^{+}=$trihexyl, tetradecylphosphonium; [SCN $]^{-}=$thiocyanate; [DCA $]^{-}=$dicyanamide; $\left[\mathrm{NTf}_{2}\right]^{-}=$bis $\{$(trifluoromethyl) sulfonyl\}imide; $[\mathrm{OTf}]^{-}=$trifluoromethanesulfonate; $[\mathrm{AcO}]^{-}=$acetate; $\left[\mathrm{MeSO}_{4}\right]^{-}=$methylsulfate; $[\mathrm{FAP}]^{-}=$trifluorotris (perfluoroethyl)phosphate; $[\mathrm{TFA}]^{-}=$ trifluoroacetate; $\left[\mathrm{OctSO}_{4}\right]^{-}=$octylsulfate.

$\left.\pi f_{\mathrm{s}} \rho\right)^{1 / 2}$ where $\rho$ and $\eta$ are the density and viscosity of the liquid and $f_{\mathrm{s}}$ is the resonant frequency. ${ }^{20}$ In impedance analysis, both the resonant frequency and bandwidth, $B$, of the crystal are measured and are functions of the liquid properties. Bandwidth is a measure of the loss of energy and of the damping of the shear mode oscillation of the liquid close to the solid-liquid interface, and so some authors prefer to define a dissipation $D=B / f_{s}$ (also equal to $Q^{-1}$ ). When the liquid is Newtonian, a frequency decrease, $\Delta f$, and a bandwidth increase, $\Delta B$, occur in proportion to the square root of the viscosity-density product,

$$
\frac{\Delta f}{f_{\mathrm{o}}}=-\frac{1}{Z_{\mathrm{q}}}\left(\frac{f_{\mathrm{s}} \eta \rho}{\pi}\right)^{12} \text { and } \frac{\Delta B}{f_{\mathrm{o}}}=\frac{2}{Z_{\mathrm{q}}}\left(\frac{f_{\mathrm{s}} \eta \rho}{\pi}\right)^{1 / 2}
$$

where the specific acoustic impedance of quartz is $Z_{\mathrm{q}}=\left(\mu_{\mathrm{q}} \rho_{\mathrm{q}}\right)^{1 / 2}=$ $8.84 \times 10^{-6} \mathrm{~kg} \mathrm{~m}^{-2} \mathrm{~s}^{-1}, f_{0}$ is the fundamental frequency and $f_{\mathrm{s}}=n f_{0}$ is the overtone frequency at which the response is measured..$^{21,22}$ Thus, by verifying that changes in resonant frequency and bandwidth are correlated, such that $\Delta f=-\Delta \mathrm{B} / 2$, eq 1 allows a determination of whether an ionic liquid has a Newtonian response. If the ionic liquid is Newtonian, either the frequency change (the Kanazawa and Gordon equation) or the bandwidth change can be used to determine the value of the viscosity-density product and from knowledge of the density, the viscosity can be deduced.

In this work, concentrations of a water-miscible roomtemperature ionic liquid, 1-butyl-3-methylimidazolium trifluoromethylsulfonate, $\left[\mathrm{C}_{4} \mathrm{mim}\right][\mathrm{OTf}]$, and a water-immiscible room temperature ionic liquid, 1-butyl-3-methylimidazolium bis(trifluoromethanesulfonyl)imide, $\left[\mathrm{C}_{4} \mathrm{mim}\right]\left[\mathrm{NTf}_{2}\right]$, are shown to be Newtonian according to impedance spectra for a $5-\mathrm{MHz}$ quartz crystal for concentrations from pure to $100 \%$ water or methanol, respectively. Results for the density-viscosity values obtained using the small-volume impedance spectra method are shown to be consistent with those obtained using a viscometer. Finally, data for 18 pure ionic liquids are presented, with Newtonian behavior being confirmed for 12 of these and the validity of a linear relationship between frequency shift and square root of viscosity-density product being confirmed up to a limit of $\sqrt{ }(\rho \eta) \approx 18 \mathrm{~kg} \mathrm{~m}^{-2} \mathrm{~s}^{-1 / 2}$.

\section{EXPERIMENTAL SECTION}

Ionic Liquids. 1-Butyl-1-methylpyrrolidinium trifluorotris(perfluoroethyl)phosphate ([ $\mathrm{C}_{4}$ mpyrr] [FAP]), 1-butyl-3-methylimidazolium trifluoroacetate $\left(\left[\mathrm{C}_{4} \mathrm{mim}\right][\mathrm{TFA}]\right)$, 1-butyl-3-methylimidazolium dicyanamide $\left(\left[\mathrm{C}_{4} \mathrm{mim}\right][\mathrm{DCA}]\right)$, 1-butyl-1-methylpyrrolidinium dicyanamide $\left(\left[\mathrm{C}_{4}\right.\right.$ mpyrr] $\left.][D C A]\right)$, 1-ethyl-3-methylimidazolium thiocyanate $\left(\left[\mathrm{C}_{2} \mathrm{mim}\right][\mathrm{SCN}]\right)$, 1-butyl-3-methylimidazolium methylsulfate $\left(\left[\mathrm{C}_{4} \mathrm{mim}\right]\left[\mathrm{MeSO}_{4}\right]\right)$, 1-butyl-3-methylimidazolium octylsulfate $\left(\left[\mathrm{C}_{4} \mathrm{mim}\right]\left[\mathrm{OctSO}_{4}\right]\right)$, and methyl-trioctylammonium trifluoroacetate $\left(\left[\mathrm{N}_{1,8,8,8}\right][\mathrm{TFA}]\right)$ were obtained from Merck (98\%). 1-Ethyl-3-methylimidazolium ethyl sulfate $\left(\left[\mathrm{C}_{2} \mathrm{mim}\right]\left[\mathrm{EtSO}_{4}\right]\right)$ was prepared by reacting 1-methylimidazole with diethyl sulfate according to previously reported procedures. ${ }^{23}$ All other ionic liquids were prepared in-house using standard literature methods from the appropriate organic halide salt. ${ }^{24,25}$ The halide content of each ionic liquid was measured by using suppressed ion chromatography ${ }^{26}$ and the characterization of each ionic liquid used is shown in Table 1.

(17) Martin, S. J.; Granstaff, V. E.; Frye, G. C. Anal. Chem. 1991, 63, 22722281.

(18) Bandey, H. L.; Hillman, A. R.; Brown, M. J.; Martin, S. J. Faraday Discuss. 1997, 107, 105-121.

(19) Bruckenstein, S.; Shay, M. Electrochim. Acta 1985, 30, 1295-1300.

(20) Kanazawa, K. K.; Gordon, J. G. Anal. Chim. Acta 1985, 175, 99-105.

(21) Bandey, H. L.; Martin, S. J.; Cernosek, R. W.; Hillman, A. R. Anal. Chem. 1999, 71, 2205-2214.

(22) Ballantine D. S.; White, R. M.; Martin, S. J.; Ricco, A. J.; Zellers, E. T.; Frye, G. C.; Wohltjen, H. Acoustic Wave Sensors: Theory, Design, \& PhysicoChemical Applications; Academic Press: San Diego, 1997.

(23) Bonhôte, P.; Dias, A. P.; Papageorgiou, N.; Kalyanasundram, K.; Grätzel, M. Inorg. Chem. 1996, 5, 1168-1178.

(24) Earle, M. J.; Katdare, S. P.; Seddon, K. R. Org. Lett. 2004, 6, 707-710.

(25) Xu, W.; Wang, L. M.; Nieman, R. A.; Angell, C. A. J. Phys. Chem. B 2003, $107,11749-11756$ 


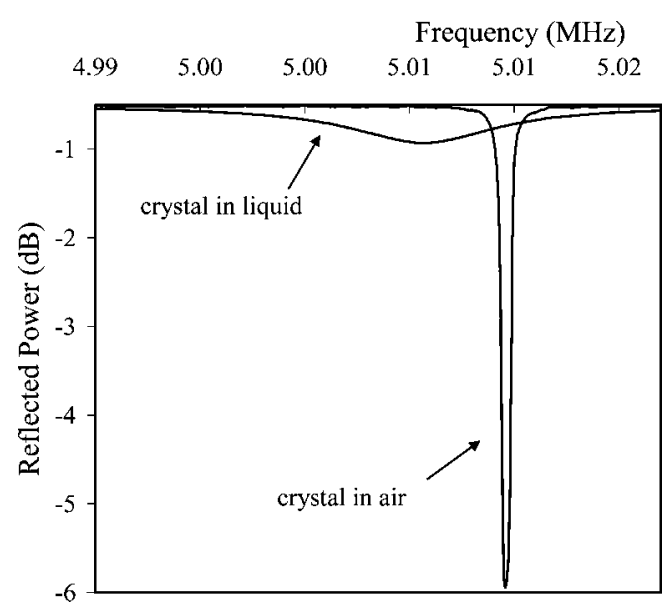

Figure 1. Quartz crystal power spectra for an unloaded crystal and one immersed in $\left[\mathrm{C}_{2} \mathrm{mim}\right]\left[\mathrm{NTf}_{2}\right]$.

Impedance Spectra. Polished quartz crystals having a fundamental frequency of $5 \mathrm{MHz}$ and diameter of $25 \mathrm{~mm}$ (Testbourne Ltd. 149211-1) were used, with the frequency spectra being collected using an Agilent Technologies E5061A Network Analyzer. Resonance spectra were recorded for crystals in air and in liquid at $25^{\circ} \mathrm{C}$ and fitted to a Butterworth van Dyke (BVD) model using a LabView program; exemplar data for the reflected power are shown in Figure 1 for an unloaded and a crystal immersed in an ionic liquid $\left(\left[\mathrm{C}_{2} \mathrm{mim}\right]\left[\mathrm{NTf}_{2}\right]\right)$. The BVD model allows a load impedance to be extracted as a series combination of a resistance and an inductance and from the best fit the resonant frequency and bandwidth are obtained. ${ }^{22} \mathrm{~A}$ brief review of this model and the procedure we used for fitting data to the resonance spectra for reflected power is reported in Roach et al. ${ }^{27}$ Spectra were obtained for the fundamental frequency and four higher overtones. Above the third harmonic, the frequency shift could be identified, but the BVD program was unable to fit accurately enough to determine the bandwidth. Previous work comparing resonant frequency shifts of various harmonics while testing the shear compliance of thin films has suggested the third harmonic produces a more accurate frequency change in response to mass/liquid loading. ${ }^{28}$ The test cell for holding the crystals was machined directly from PTFE leaving a 20-mm-diameter chamber and 2.5-mm-wide raised lip acting as an O-ring seal and requiring only $40 \mu \mathrm{L}$ of test volume of liquid for satisfactory operation. To reduce the absorption of moisture, the equipment was set up inside a glovebag under argon. Crystals were cleaned in distilled water and then methanol and blown dry using nitrogen prior to each measurement. A typical measurement time for introducing the liquid to the cell and taking the resonance spectra for the full range of harmonics was under $2 \mathrm{~min}$.

Viscometer and Density Data. Measurements of viscosity and density were made using a Brookfield DV-II+ programmable viscometer, and a DMA 4500 density/specific gravity/concentration meter; these methods require 1.5 and $0.5 \mathrm{~mL}$ of liquid, respectively. Before use, all the ionic liquids were dried using a heated oil bath at $60{ }^{\circ} \mathrm{C}$ while subjected to a vacuum (1 Torr) and left overnight to facilitate maximum water removal; water

(26) Villagrán, C.; Deetlefs, M.; Pitner, W. R.; Hardacre, C. Anal. Chem. 2004, 76, 2118-2123.

(27) Roach, P. A.; McHale, G.; Evans, C. R.; Shirtcliffe, N. J.; Newton, M. I. Langmuir 2007, 23, 9823-9830.

(28) Johannsmann, D. J. Appl. Phys. 2001, 89, 6356-6364. content of the ionic liquid was measured using a Karl Fischer titrator. A series of poly(dimethylsiloxane) (PDMS) oils (Aldrich) covering viscosities from 1 to $100000 \mathrm{cP}$ were used to give a comparison fluid that is known to deviate from a Newtonian behavior at high molecular weight. The temperature for both density and viscosity measurements could be controlled using a water bath and were set to $25^{\circ} \mathrm{C}$, which was the value recorded at the time the QCM measurements were made Table 2.

\section{RESULTS AND DISCUSSION}

Determination of Newtonian Liquid Behavior. The change in bandwidth or change in frequency of the $\mathrm{QCM}$ allows the viscosity-density product of the liquid under test to be calculated using the linear relationships given by eq 1 provided the liquid is a Newtonian fluid. To test this linearity, Figure 2 a shows the change in fundamental frequency and Figure $2 \mathrm{~b}$ the corresponding change in bandwidth as a function of square root of the density-viscosity product obtained using the viscometer and density meter for a range of concentrations of two ionic liquids (water-miscible $\left[\mathrm{C}_{4} \mathrm{mim}\right][\mathrm{OTf}]$ diluted in water, squares, and waterimmiscible $\left[\mathrm{C}_{4} \mathrm{mim}\right]\left[\mathrm{NTf}_{2}\right]$ diluted in methanol, triangles). These data suggest that the QCM could be used to determine the square root of the viscosity-density product of an ionic liquid directly from small-volume samples. However, a linear response in Figure $2 \mathrm{a}$ or Figure $2 \mathrm{~b}$ does not directly confirm that the liquid is Newtonian and, hence, that eq 1 can be applied.

Figure 3 presents the data for the various concentrations of ionic liquids as a change in fundamental frequency against change in bandwidth. The frequency shift and bandwidth increase data are welldescribed by a linear relationship. To illustrate typical results for a non-Newtonian liquid, Figure 2 and Figure 3 also present data for a range of poly(dimethylsiloxane) oils (circles), which are known to deviate significantly from Newtonian behavior at higher molecular weight; this deviation can be clearly observed above a change in frequency of $3 \mathrm{kHz}$ corresponding to a viscosity of $10 \mathrm{cP}$. For the ionic liquids, the majority of data in Figure 3 follow the solid line with a slope of 0.5 , which is the prediction for a Newtonian liquid; the inset confirms this for concentrations up to $90 \%$. At concentrations of ionic liquid above $90 \%$, there is a small deviation with a slightly larger bandwidth than predicted for a given frequency shift. This is probably due to the increased difficulty in accurately fitting the resonant curves for the bandwidth for the pure ionic liquids with high viscosity (high damping), making the identification of the resonant frequency more reliable than the determination of the bandwidth. In addition, although the samples were measured in a glovebag, the high hygroscopicity of the ionic liquids and the high sensitivity of viscosity on the water content for the pure ionic liquids ${ }^{29}$ may also contribute to the slight variance observed.

Third Harmonic Data for Viscosity-Density Product. The frequency change can be converted to square root of viscosity-density product using the Kanazawa and Gordon equation (eq 1). Figure 4 shows the square root of the density-viscosity product plotted as a function of concentration of the water-miscible $\left[\mathrm{C}_{4} \mathrm{mim}\right]$ [OTf] using the QCM frequency shift measured at the third harmonic (diamonds) and the corresponding product calculated from the independent viscometer and density meter measurements (squares).

(29) Seddon, K. R.; Stark, A.; Torres, M. J. Pure Appl. Chem. 2000, 72, 22752287. 
Table 2. Comparison of the $(\rho \eta)^{1 / 2}$ Determined from the Third Harmonic of Quartz Crystal and from Separate Measurements Using a Viscometer and Density Meter at $25{ }^{\circ} \mathrm{C}$

\begin{tabular}{|c|c|c|c|}
\hline ionic liquid & $\begin{array}{l}\text { included in Figure } \\
\text { 6a (Newtonian test) }\end{array}$ & $\begin{array}{l}(\rho \eta)^{1 / 2}\left(\mathrm{~kg} \mathrm{~m}^{-2} \mathrm{~s}^{-1 / 2}\right) \text { third } \\
\text { harmonic of quartz crystal }\end{array}$ & $\begin{array}{l}\quad(\rho \eta)^{1 / 2}\left(\mathrm{~kg} \mathrm{~m}^{-2} \mathrm{~s}^{-1 / 2}\right) \\
\text { viscometer-density meter }( \pm 1 \%)\end{array}$ \\
\hline$\left[\mathrm{C}_{2} \mathrm{mim}\right][\mathrm{SCN}]$ & $\sqrt{ }$ & $4.5 \pm 0.6$ & 5.1 \\
\hline$\left[\mathrm{C}_{4} \mathrm{mim}\right][\mathrm{DCA}]$ & $\sqrt{ }$ & $5.6 \pm 0.1$ & 5.5 \\
\hline$\left[\mathrm{C}_{4} \mathrm{mpyrr}\right][\mathrm{DCA}]$ & $\sqrt{ }$ & $5.5 \pm 0.1$ & 6.1 \\
\hline$\left[\mathrm{C}_{2} \mathrm{mim}\right]\left[\mathrm{NTf}_{2}\right]$ & $\sqrt{ }$ & $6.4 \pm 0.6$ & 7.4 \\
\hline$\left[\mathrm{C}_{4} \mathrm{mim}\right]\left[\mathrm{NTf}_{2}\right]$ & $\sqrt{ }$ & $8.2 \pm 0.2$ & 8.5 \\
\hline$\left[\mathrm{C}_{4} \operatorname{mim}\right][\mathrm{OTf}]$ & $\sqrt{ }$ & $10.0 \pm 0.9$ & 10.4 \\
\hline$\left[\mathrm{C}_{4} \mathrm{mpyrr}\right]\left[\mathrm{NTf}_{2}\right]$ & $\sqrt{ }$ & $10.1 \pm 0.3$ & 10.5 \\
\hline$\left[\mathrm{C}_{6} \mathrm{mim}\right]\left[\mathrm{NTf}_{2}\right]$ & $\sqrt{ }$ & $9.8 \pm 0.5$ & 10.4 \\
\hline$\left[\mathrm{C}_{2} \mathrm{mim}\right]\left[\mathrm{EtSO}_{4}\right]$ & $\sqrt{ }$ & $10.7 \pm 0.6$ & 11.0 \\
\hline$\left[\mathrm{C}_{8} \operatorname{mim}\right]\left[\mathrm{NTf}_{2}\right]$ & $\sqrt{ }$ & $9.6 \pm 0.9$ & 11.2 \\
\hline$\left[\mathrm{C}_{10} \mathrm{mim}\right]\left[\mathrm{NTf}_{2}\right]$ & $\sqrt{ }$ & $10.9 \pm 0.5$ & 12.4 \\
\hline$\left[\mathrm{C}_{4} \mathrm{mim}\right][\mathrm{AcO}]$ & $\mathrm{X}$ & $11.8 \pm 0.2$ & 13.2 \\
\hline$\left[\mathrm{C}_{4} \mathrm{mim}\right]\left[\mathrm{MeSO}_{4}\right]$ & $\mathrm{X}$ & $13.8 \pm 0.8$ & 15.1 \\
\hline$\left[\mathrm{C}_{4} \mathrm{mpyrr}\right][\mathrm{FAP}]$ & $\mathrm{X}$ & $15.3 \pm 2.1$ & 18.7 \\
\hline$\left[\mathrm{P}_{6,6,6,14}\right]\left[\mathrm{NTf}_{2}\right]$ & $\mathrm{X}$ & $10.6 \pm 0.6$ & 18.9 \\
\hline$\left[\mathrm{C}_{4} \mathrm{mim}\right][\mathrm{TFA}]$ & $\mathrm{X}$ & $14.6 \pm 0.1$ & 21.1 \\
\hline$\left[\mathrm{C}_{4} \mathrm{mim}\right]\left[\mathrm{OctSO}_{4}\right]$ & $\mathrm{X}$ & $10.9 \pm 1.1$ & 30.9 \\
\hline$\left[\mathrm{N}_{1,8,8,8}\right][\mathrm{TFA}]$ & $\mathrm{X}$ & $15.3 \pm 3.6$ & 40.6 \\
\hline
\end{tabular}

The inset in Figure 4shows the corresponding square root of the density-viscosity product for the QCM and non-QCM techniques; the straight line is a best fit with a slope of 0.96 . The inset also provides a comparison of the density-viscosity product calculated from the third harmonic (diamonds) and from the fundamental (circles) of the quartz crystal. Both the fundamental and the third harmonic data agree within experimental error with the non-QCM measurements at lower viscosities, but at the highest viscosity, the data from the fundamental mode slightly underestimate the viscosity-density product. In contrast, the third harmonic data remain in agreement with viscometer and density meter data over the full concentration range up to pure ionic liquid. We found that the third harmonic gave better agreement with the non-QCM measurements than all the other harmonics measured. The data for the water-immiscible ionic liquid $\left[\mathrm{C}_{4}\right.$ mim $]\left[\mathrm{NTf}_{2}\right]$ also resulted in the same conclusions with the third harmonic data providing a lowvolume sample measurement of density-viscosity product consistent with the results using the larger volumes in the viscometer and density meter; the data are shown in Figure 5 . In both cases, the largest error from repeated measurements $(\sim \pm 10 \%)$ occurs for the pure liquids, which given the hygroscopic nature of these roomtemperature ionic liquids and sensitive dependence on liquid composition of the viscosity, is not surprising.

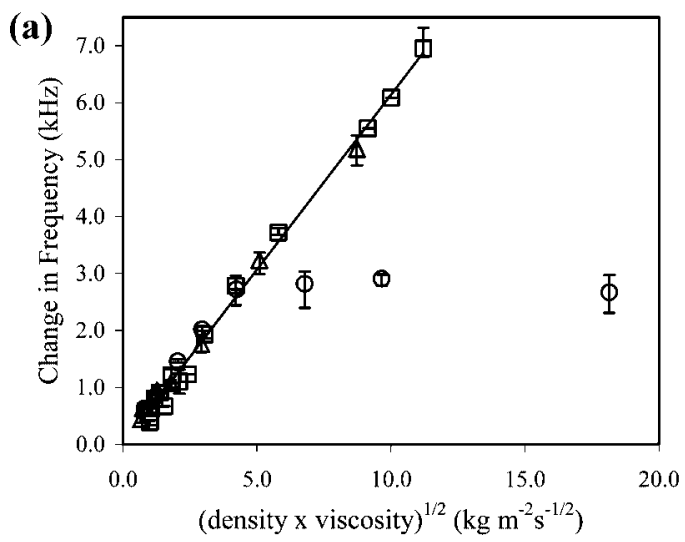

Pure Ionic Liquids. A set of 18 pure ionic liquids was tested using both the small-volume quartz crystal impedance technique and the large-volume viscometer. Figure 6a shows a linear correlation between changes in resonant frequency, $\Delta f_{\mathrm{s}}$, and bandwidth, $\Delta B$, for 11 of the ionic liquids for which reliable fits of the bandwidth were obtained at the fundamental frequency (the first 11 ionic liquids in Table 1); replicate measurements have been included. All of these ionic liquids are reasonably described by the test for Newtonian behavior, $\Delta f_{s}=-\Delta B / 2$, although the best fit to the data gives a gradient of 0.439 (solid line). Figure $6 \mathrm{~b}$ shows the change in resonant frequency as a function of the square root of viscosity-density product measured using the viscometer and density meter for all 18 ionic liquids. There is a clear threshold at around $\sqrt{ }(\rho \eta) \approx 18.7 \mathrm{~kg} \mathrm{~m}^{-2} \mathrm{~s}^{-1 / 2}$ after which two ionic liquids, $\left[\mathrm{P}_{6,6,6,14}\right]\left[\mathrm{NTf}_{2}\right]$ and $\left[\mathrm{C}_{4} \mathrm{mim}\right][\mathrm{TFA}]$, deviate slightly from the linear prediction and a further two, $\left[\mathrm{C}_{4} \mathrm{mim}\right]\left[\mathrm{OctSO}_{4}\right]$ and $\left[\mathrm{N}_{1,8,8,8}\right][\mathrm{TFA}]$, deviate significantly from the linear prediction. At these high levels of viscosity where resonant curves are very broad and difficult to fit accurately, however, it was possible to fit the full resonant curve for one of these, $\left[\mathrm{C}_{4} \mathrm{mim}\right]\left[\mathrm{OctSO}_{4}\right]$, and it did satisfy the Newtonian criteria given by, $\Delta f_{\mathrm{s}}=-\Delta B / 2$. This would indicate that all ionic liquids tested for which the quartz crystal method was able to provide accurate results (i.e., up to $\sqrt{ }(\rho \eta) \approx 18 \mathrm{~kg} \mathrm{~m}^{-2} \mathrm{~s}^{-1 / 2}$ )

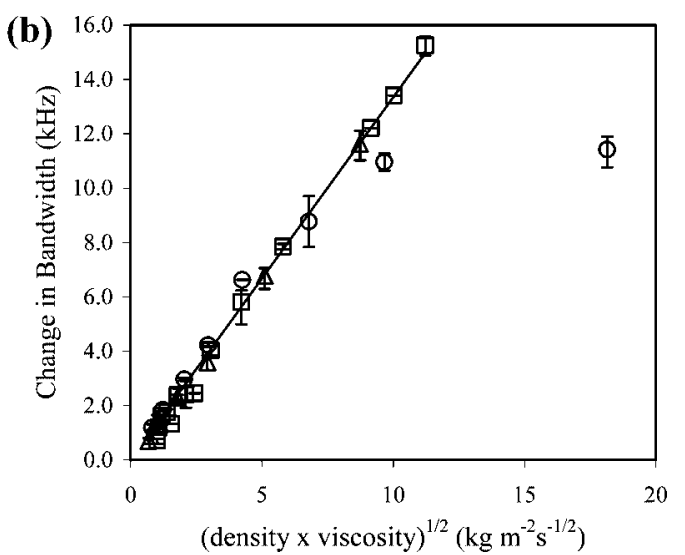

Figure 2. Changes in (a) resonant frequency and (b) bandwidth, as a function of viscosity-density product. Data show [C $\left.\mathrm{C}_{4} \mathrm{mim}\right][\mathrm{OTf}]$ up to $100 \%$ concentration in water (squares), $\left[\mathrm{C}_{4} \mathrm{mim}\right]\left[\mathrm{NTf}_{2}\right]$ up to $100 \%$ concentration in methanol (triangles), and a range of poly(dimethylsiloxane) oils (circles). 


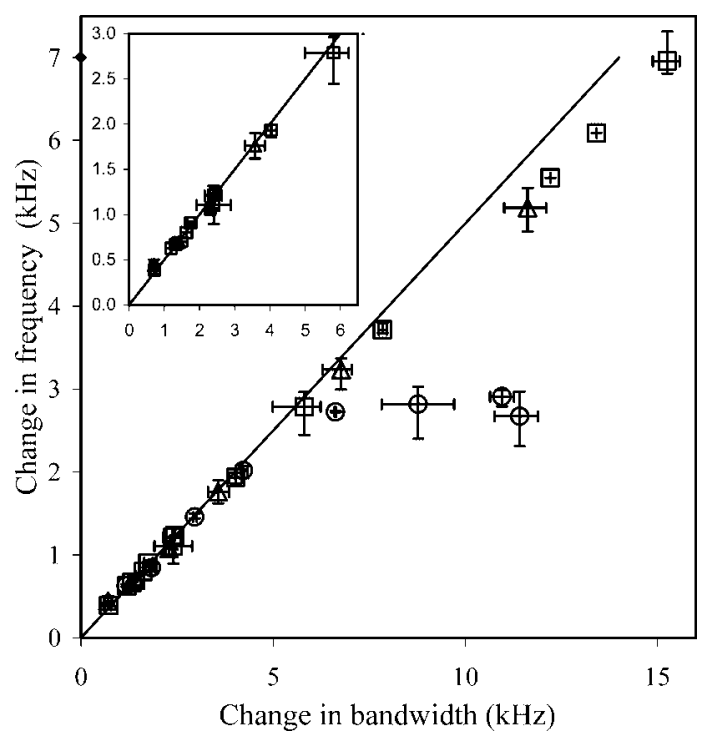

Figure 3. Data presented as change in frequency against change in bandwidth to test for Newtonian response. The poly(dimethylsiloxane) oils (circles) deviate significantly from Newtonian behavior (Kanazawa and Gordon equation shown by the solid line) at high molecular weight, but the $\left[\mathrm{C}_{4} \mathrm{mim}\right][\mathrm{OTf}]$ (squares) and $\left[\mathrm{C}_{4} \mathrm{mim}\right]\left[\mathrm{NTf}_{2}\right]$ (triangles) remain Newtonian. The inset shows ionic liquids up to a concentration of $90 \%$.

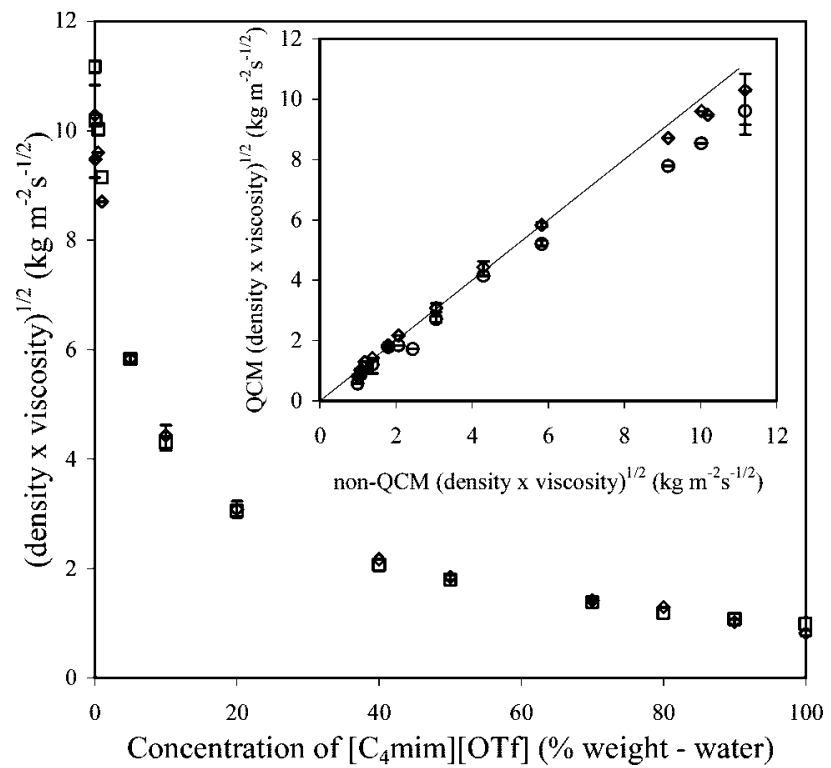

Figure 4. Density-viscosity dependence on concentration for the water-miscible ionic liquid [ $\left.\mathrm{C}_{4} \mathrm{mim}\right][\mathrm{OTf}]$ determined by viscometer (squares) and the third harmonic of the quartz crystal (diamonds). Inset shows comparison of the quartz crystal data from the fundamental (circles) and third harmonic (diamonds); solid line is a best fit with slope of 0.96 .

were Newtonian. Figure 7 shows the correlation of the square root of viscosity-density product estimated using the third harmonic frequency shift of the quartz crystal with the data from the viscometer and density meter for the 16 pure ionic liquids satisfying the linear prediction or having a slight deviation from the linear prediction; Table 1 gives the average values measured for all 18 liquids measured. For data points up to $\sqrt{ }(\rho \eta) \approx 18 \mathrm{~kg}$ $\mathrm{m}^{-2} \mathrm{~s}^{-1 / 2}$, the data can be fitted by $\sqrt{ }(\rho \eta)_{\mathrm{QCM}}=0.92 \sqrt{ }(\rho \eta)_{\text {viscometer, }}$ thus indicating around a $10 \%$ underestimate by the quartz crystal

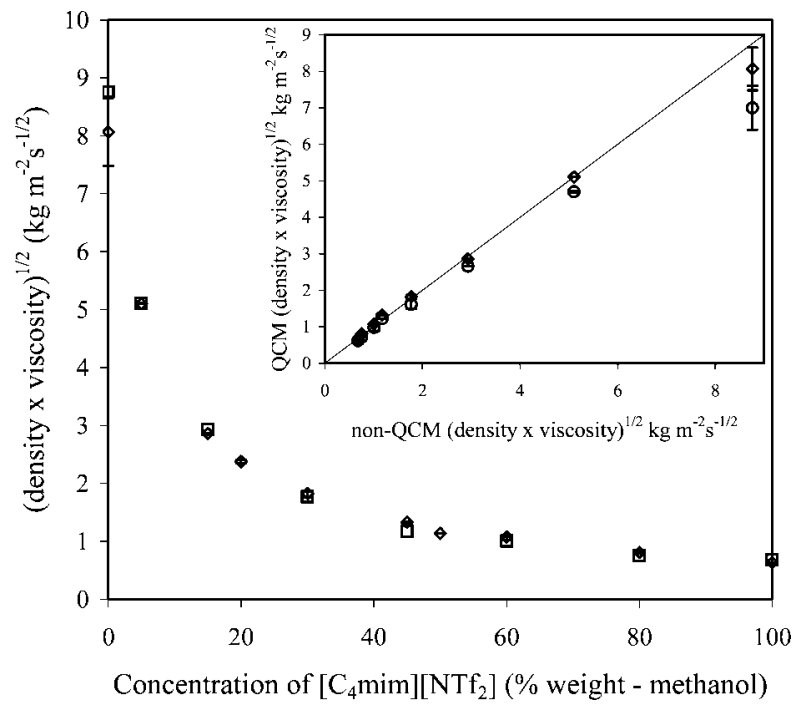

Figure 5. Density-viscosity dependence on concentration for the water-immiscible ionic liquid $\left[\mathrm{C}_{4}\right.$ mim] $\left[\mathrm{NTf}_{2}\right]$ determined by viscometer (squares) and the third harmonic of the quartz crystal (diamonds). Inset shows comparison of the quartz crystal data from the fundamental (circles) and third harmonic (diamonds).

impedance method compared to the viscometer. However, in a high-throughput application of the technique, such an underestimate could be corrected by using a calibrated value for the numerical coefficient in eq 1 rather than the theoretical value from the Kanazawa and Gordon equation.

Clearly the product of the density and viscosity only has limited application and usually the individual values are required, for example, in process design. Recently, predictive modeling of density data based on molar volume calculations of the constituent ions has been reported by a number of groups. ${ }^{30-33}$ Jacquemin et al. showed using $>2000$ data points that the density could be predicted with an uncertainty of $0.48 \%$ as a function of temperature. ${ }^{34}$ This level of predictability may be used in conjunction with the QCM-derived value for the $\rho \eta$ and therefore provide a predicted viscosity for a given ionic liquid. This is a significant advance given that conventional measurements of $\eta$ requires $>1.5$ $\mathrm{mL}$ of ionic liquid whereas by this method the sample size may be reduced to $40 \mu \mathrm{L}$.

The measurements reported herein are in good agreement with previously reported data on the effect of shear rate on viscosity for ionic liquids. Seddon et al. studied the viscosity of $\left[\mathrm{C}_{n} \operatorname{mim}\right]\left[\mathrm{BF}_{4}\right](n=4$ to $n=12)$ and $\left[\mathrm{C}_{n} \operatorname{mim}\right]\left[\mathrm{PF}_{6}\right](n=4$ to $n$ $=12$ ) ionic liquids and found that for all except $\left[\mathrm{C}_{12} \mathrm{mim}\right]\left[\mathrm{BF}_{4}\right]$ the viscosity for independent of shear rate was indicative of Newtonian behavior. ${ }^{35}$ While for $\left[\mathrm{C}_{12} \mathrm{mim}\right]\left[\mathrm{BF}_{4}\right]$ above $65^{\circ} \mathrm{C}$ this was also true, below this temperature non-Newtonian behavior was observed due to the phase transition from the isotropic liquid phase into the liquid crystalline region. Non-Newtonian behavior has also been reported for benzyl-functionalized imidazolium-based

(30) Kim, Y. S.; Choi, W. Y.; Jang, J. H.; Yoo, K.-P.; Lee, C. S. Fluid Phase Equilib. 2005, 228, 439-445.

(31) Kim, Y. S.; Jang, J. H.; Lim, D. B.; Kang, J. W.; Lee, C. S. Fluid Phase Equilib. 2007, 256, 70-74.

(32) Gardas, R. L.; Coutinho, J. A. P. Fluid Phase Equilib. 2008, 263, 26-32.

(33) Ye, C.; Shreeve, J. M. J. Phys. Chem. A 2007, 111, 1456-1461.

(34) Jacquemin, J.; Ge, R.; Nancarrow, P.; Rooney, D. W.; Gomes, M. F. C.; Padua, A. A. H.; Hardacre, C. J. Chem. Eng. Data 2008, 53, 716-726.

(35) Seddon, K. R.; Stark, A.; Torres, M. J. Clean Solvents 2002, 819, 34-49. 

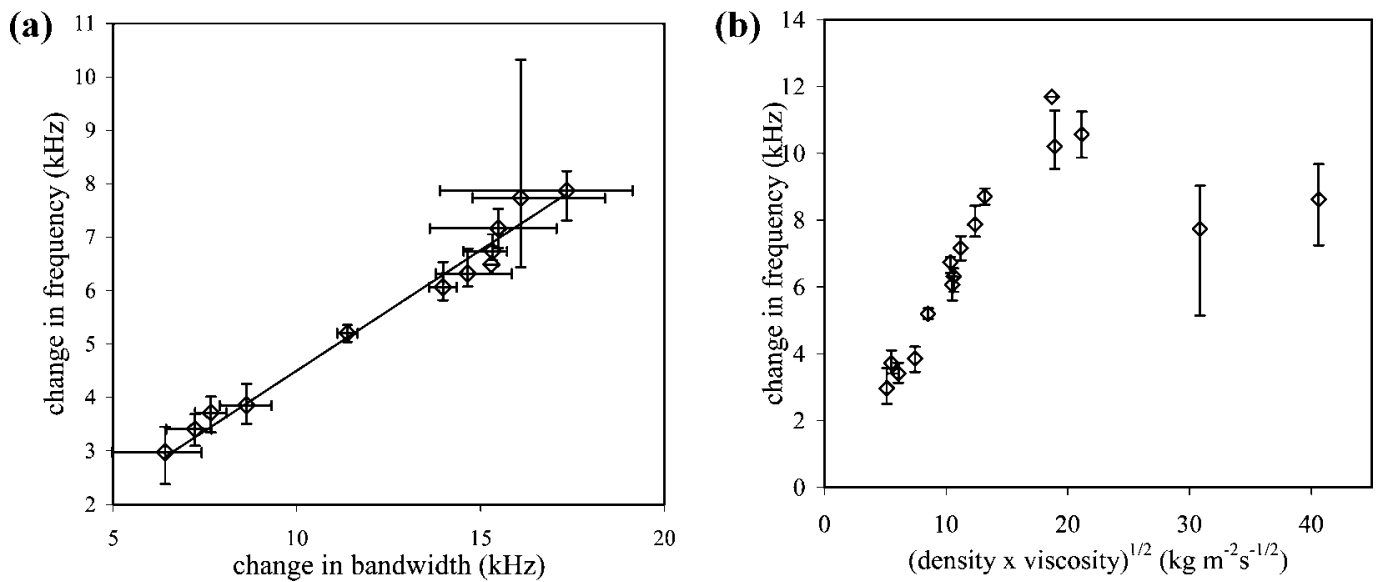

Figure 6. Fundamental mode data for 19 pure ionic liquids. (a) Correlation between change in resonant frequency and change in bandwidth demonstrating Newtonian behavior, (b) change in resonant frequency as a function of viscosity-density product. The data are described by a linear relationship up to $\sqrt{ }(\rho \eta) \approx 18.7 \mathrm{~kg} \mathrm{~m}^{-2} \mathrm{~s}^{-1 / 2}$.

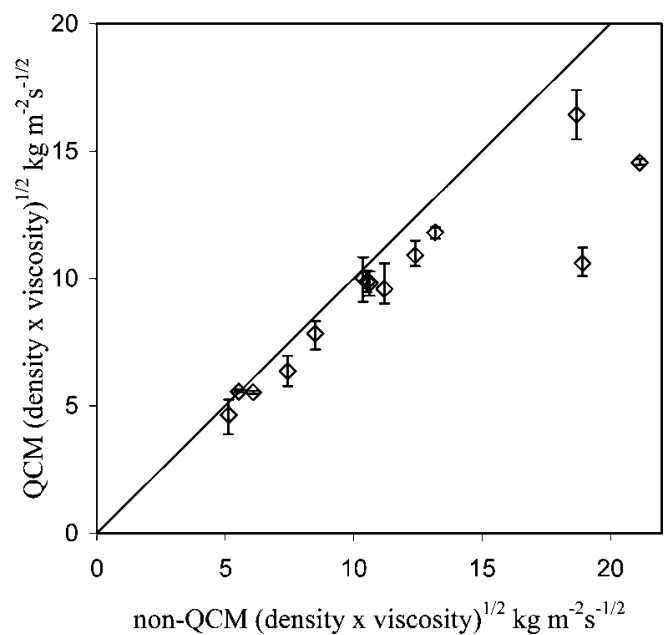

Figure 7. Correlation between density-viscosity product for 17 pure ionic liquids determined using viscometer and density meter and by using the change in resonant frequency of the quartz crystal at the third harmonic. The solid line has a slope of unity. The linear correlation breaks down for the highest viscosity ionic liquids at around $\sqrt{ }(\rho \eta) \approx 18 \mathrm{~kg} \mathrm{~m}^{-2} \mathrm{~s}^{-1 / 2}$.

ionic liquids by Kulkarni et al. as well as a number of $\left[\mathrm{C}_{10} \mathrm{mim}\right]\left[\mathrm{CF}_{3} \mathrm{COO}\right],\left[\mathrm{C}_{10} \mathrm{mim}\right]\left[\mathrm{NTf}_{2}\right]$, and $\left[\mathrm{C}_{10} \mathrm{mim}\right][\mathrm{SCN}]{ }^{36}$ Interestingly, this is not found in the QCM data where $\left[\mathrm{C}_{10} \mathrm{mim}\right]\left[\mathrm{NTf}_{2}\right]$ fits the linear trend of eq 1 . Although, the addition of solutes to ionic liquids has been shown to result in nonNewtonian behavior, this has predominantly been for ionic liquids containing functionalized cations, for example, where strong hydrogen bonding can occur between the solute and ionic liquid. ${ }^{37-39} \mathrm{Li}$ et al. showed that the plastic and then Newtonian behavior was observed as the shear rate increased for mixtures of $\left[\mathrm{Me}_{3} \mathrm{NC}_{2} \mathrm{H}_{4} \mathrm{OH}\right]\left[\mathrm{Zn}_{2} \mathrm{Cl}_{5}\right]$ and ethanol. ${ }^{39}$ Herein, where the ionic liquid-water interaction may be considered as weaker, only Newtonian behavior was observed. Recent calculations have shown that non-Newtonian behavior may be expected for many

(36) Kulkarni, P. S.; Branco, L. C.; Crespo, J. G.; Nunes, M. C.; Raymundo, A.; Afonso, C. A. M. Chem.:Eur. J. 2007, 13, 8478-8488.

(37) Guo, Z.; Xu, X. B. Green Chem. 2006, 8, 54-62.

(38) Chagnes, A.; Tougui, A.; Carre, B.; Ranganathan, N.; Lemordant, D. J. Sol. Chem. 2004, 33, 247-255.

(39) Li, Q. M.; Wu, G. Z.; Liu, Y. D.; Luo, Y. S. Appl. Rheol. 2006, 16, 334-339. ionic liquids, even those thought as showing Newtonian behavior on the macroscale, if the ionic liquid is confined in microchannels, for example. ${ }^{40}$ The QCM technique coupled with microchannel devices will enable this prediction to be studied in detail and is the subject of an ongoing study.

\section{CONCLUSION}

In this article, we have shown that quartz crystal impedance analysis can be used to determine whether mixtures of a watermiscible and a water-immiscible ionic liquid with water and methanol, respectively, have Newtonian responses when subject to a high-frequency oscillation. For ionic liquids with a Newtonian response, it has been shown that viscosity-density products can be determined from small-volume samples without the need for calibration liquids. The results also demonstrate that the third harmonic of the crystal resonance provides the greatest consistency over the full range of concentrations with results obtained using a viscometer and density meter. Data obtained for 12 pure ionic liquids were found to show Newtonian responses with correlated shifts in quartz crystal frequency and bandwidth. The change in frequency for pure ionic liquids was directly proportional to the square root of the viscosity-density product for values up to $18 \mathrm{~kg} \mathrm{~m}^{-2} \mathrm{~s}^{-1 / 2}$. The ability of the quartz crystal method to determine viscosity-density products of ionic liquids should allow the development of high-throughput measurements of physical properties for ionic liquids. A natural extension of this work is to higher frequency acoustic wave devices, such as shear horizontally polarized surface acoustic wave and acoustic plate mode devices, ${ }^{41,42}$ which can be used with smaller volumes of liquid and which can be integrated into microfluidic devices.

\section{ACKNOWLEDGMENT}

This work has been supported by the UK Engineering \& Physical Sciences Research Council (EPSRC) under grants EP/ D03826X/1, EP/D038294/1 and EP/D038995/1.

Received for review March 8, 2008. Accepted June 4, 2008.

\section{AC800490Q}

(40) Hu, Z. H.; Margulis, C. J. Acc. Chem. Res. 2007, 40, 1097-1105.

(41) Vellekoop, M. J. Ultrasonics 1998, 36, 7-14.

(42) McHale, G. Meas. Sci. Technol 2003, 14, 1847-1853. 